\title{
Reflection on Creating an Integrated Organization Mode of Multimodal Transport and Urban Distribution*
}

\author{
De'ai Deng \\ Hunan Modern Logistics College \\ Changsha, China
}

\begin{abstract}
An integration of resources related multimodal transport and urban distribution and unblocking channels for seamless connection between multimodal transport and urban distribution will be a great help to solve problems of fragmented operation and hard logistics, and to improve the logistics efficiency and reduce the costs of logistics. Based on the significance of study, the current domestic and foreign development, the existing foundation and conditions as well as the project implementation proposals, the article raises assumptions for the research project, which will lay a foundation for implementing the project research.
\end{abstract}

Keywords-multimodal transport; urban distribution; integrated organization mode

\section{INTRODUCTION}

In order to carry out the decisions and deployment of the CPC Central Committee and the State Council on advancing the adjustment of transport structure, win the battle for a blue sky, fight against pollutions, improve the overall transport efficiency and to lower logistics costs, a "Three-year Action Plan to Promote the Adjustment of Transport Structure (2018-2020)" has been formulated by the General Office of the State Council, which makes it clear to carry out multimodal transport and urban distribution projects as "promote the highway and railway transport for materials needed for urban production and living", "Further advance the multimodal transport demonstration projects" and "Advance green urban products distribution demonstration projects" and more. In order to deepen the action plan, it need to guide cities owning advantages of resources in multimodal transport in Hunan province to fully exert the advantages of resources of their own, actively explore new models for "Coordinating organization for the integration of multimodal transport and urban distribution", integrate resources of multimodal transport and urban distribution, unblock channels for seamless connection between the same, so as to solve problems as fragmented operation and hard logistics, improving the logistics efficiency and lowing costs of the same.

*Achievements of "Preliminary Reflection on Creating an Integrated Organization Mode of Multimodal Transport and Urban Distribution" under Science \&Technology Projects of Hunan Department of Transportation.

\section{SIGNIFICANCE}

A project study may help to achieve the integration of logistics resources related to supply chains, conducting a unified control and launching unified actions, which can lower costs of the whole supply chains, raising competitiveness of the enterprises concerned.

The project study may help to optimize the allocations of social resources, and integrate the multimodal transport and urban distribution as a community of economic interests, forming a benefit economy with multimodal transport and urban distribution coordinated mutually for cooperation and stirring enthusiasm of the two to optimize the economic operation environment of the whole society.

The project aims to meet the needs of supply chains for logistics service

In order to achieve the rapid circulation and integration of logistics, information and funds, and ensure the supply chains to run with high efficiency and in order, it is required that logistics services should meet the needs of supply chains in node efficiency, timeliness, information transparency and services, etc.

- Node efficiency: The supply chains will be involved in links as producers, logistics providers and customers, as well as nodes as distribution centers, logistics parks, ports, airports, storage yards and more, which require that the container -based multimodal transport and urban distribution should adopt smart, standard and information-based facilities, equipment and technologies in order for highly efficient connection and coordination between links and nodes.

- Timeliness: Logistics providers should take charge of estimating and judging the whole logistics course as per the supply chains, and adjust the logistics schedule in order to deliver products to customers within a given time, creating it convenient for customers for immediate production.

- Information transparency: Those which participate in the logistics should exchange and share information about logistics in time as per the supply chains, with 
based multimodal transport and urban distribution are well connected. reduced.

- Services: The logistics providers should provide different customers with multi-level and diversified logistics services as per the supply chains (as basic service and value-added service), making it available for customers to select.

The project aims to meet the needs of multimodal transport and urban distribution development

Being a single form of transport organization, main purpose of traditional container-based multimodal transport is to provide customers with high-quality and low-cost transportation services, whose door-to-door transport service is limited only to the trunk transport, and it is difficult to extend to branch transports (as urban distribution, especially community distribution); the urban distribution, as an necessary point for the whole logistics chain, take charge to deliver products to customers ultimately. Only when trunk branch connection and integration are achieved, can customers be provided with true door-to-door whole-course transport service.

\section{STATUS QUO IN CHINA AND FOREIGN COUNTRIES}

\section{A. Development of Multimodal Transport}

Multimodal transport, the leading project for the development of logistics, is an efficient way to improve efficiency and lower costs in logistics and the main direction to improve the efficiency of integrated transport services. In 2018, the multimodal transport in China took on a good momentum in comprehensive development, going from cognitive to all-round practice. The railway -based railway transport throughout the country in the same year reached $13,751,000$ TEU, with a year-on-year growth rate of $33.4 \%$, and continuously the third year with railway-based container transport increased by more than $30 \%$. It is expected to reach 20 million TEUs in 2020, doubled from 2017. After three years of rapid growth in multimodal transport, the multimodal transport market in the country has more space for development. It is expected that the sea-rail intermodal transport and the international rail transport are still in a strong increase with double digits. With the continuous improvement of air cargo capacity, the fast-growing postal couriers will also adopt multimodal transport services, together with the land and air transport services. With the "transport and trade integration" and the "warehouse and trade integration" models applied, the logistics service models are always innovated, and the multimodal transport services are extended more than ever, and the effect of increased demands that the multimodal transport in markets brings begin to appear.

\section{B. Research Project}

The integration of container-based multimodal transport and urban distribution aims to optimize resources allocation, raise the logistic efficiency, economic and social benefits through a full-course logistic service where the container-
Currently there are few studies on the project at home and abroad. With the keywords as multimodal transport + urban distribution sought in CNKI database, only one article related is found: He Yingying, Sun Jiaqing, Shi Shichao (2018) from Dalian Maritime University thought that the multimodal transport and urban distribution own advantages and disadvantages of their own respectively, and the integrated development can be achieved with characteristics of their own through win-win.

\section{EXISTING FOUNDATIONS AND CONDITIONS}

In earlier stages, members of the research team carried out extensive researches on the multimodal transport and urban distribution, which has laid a solid foundation for the research project.

The research has rich literatures, clear goals, solid theories, and reasonable thought, with economics, management-related disciplines and systems engineering theories applied comprehensively, it is feasible in theory.

Applicants and main members, who come from multidisciplinary professional fields as engineering, management, economics and more, have good capabilities of scientific research and relevant accumulations, and it is a team for a long-term cooperation, capable of scientific research.

Members of the research team have mastered advanced technologies in modeling and simulation optimization, investigation analysis and empirical experimental methods, capable of scientific method and feasibility.

The organizations where applicant serve have owned advanced lab in logistics management and an Internet of Things (IoT) engineering, and established production, learning and research demonstration base for logistics supply chain management at provincial level, as well as advanced system and simulation software for the same. The authorities where applicants are governed have established a long term cooperation of research with enterprises, making it feasible for research.

The guarantee of time and data and equipment is enough to complete the research. Members of the project team consist of teachers from colleges and universities, who have adequate time for the research; and the library of the colleges and universities, facilities of Hunan Modern Logistics College can be relied on to guarantee the study.

\section{PROJECT IMPLEMENTATION PLAN}

\section{A. Key Problems to Be Solved}

Key problems to be solved in the research project include: first, to build an overall framework of the integration mode of multimodal transport and urban distribution; second, based on situations in Changsha, Hunan province, it needs to carry out empirical researches, raise a specific organization mode and implementation plan for the multimodal transport and urban distribution so as to promote the development of 
to grasp dynamic state of current research progress and achievements, laying a theoretical foundation for the project research

c) Stage of survey and research: It is to conduct onthe-spot surveys on multimodal transport stations, enterprises and urban distribution providers in Hunan province, and cooperate with relevant authorities, industrial organizations and more in order to grasp the status quo, problems and development trends related to the multimodal transport and urban distribution.

d) Stage of research: Based on literature research in early stages and survey results in two stages, it is to carry out in-depth research on the integration of multimodal transport and urban distribution so as to build an integrated mode for organization.

e) Stage of empirical application: It is to start an empirical application for the project in Changsha and further correct and improve the integration of multimodal transport and urban distribution.

f) Results summary and project conclusion:It is to widely ask for opinions from authorities and experts for conclusions.

\section{TECHNICAL AND ECONOMIC INDICATORS}

The project research will promote the integration of multimodal transport and urban distribution to form an integration of organizational mode, and will effectively improve the logistics and reduce costs of logistics distribution. It is preliminarily estimated that it will increase efficiency of urban distribution by $15 \%$ and reduce distribution costs by $15 \%$ or more.

\section{CONCLUSION}

The study focuses on the integration of multimodal transport and urban distribution, conducting comprehensive and in-depth research and analysis upon the multimodal transport, urban distribution and integration of the two. Especially if depending on a single project only, it may do harm to the project research, so, the project research is done on the basis of the whole industry but not some project, which is only applied in pilot enterprises during the stage of empirical research.

\section{REFERENCES}

[1] Wang Yangkun, Modern Multimodal Transport Development of Economic Organization of the Same [D]. Beijing Jiaotong University, 2010. (in Chinese)

[2] Liu Jie, He Shiwei, Song Rui and Li Haodong, Studies on Optimizing Dynamic Ways for Multimodal Transport on the Basis of Transport Modes [J]. Journal of the China Railway Society, 2011(10) (in Chinese)

[3] Lyu Fangyu, Thought about Multimodal Transport Development in China [J]. Zhengzhou Railway Science \& Technology, Issue 2, 2018. (in Chinese)

[4] Liu Chengdong, Investigation and Discussion on Multimodal Transport in North America [J]. Maritime China, Issue 10, 2019. (in Chinese) 
[5] Fan Zhenning, Du Jiangtan and Lin Tan, Speed-up the Multimodal Transport Development: Inspiration of US Experience [J]. China Transportation Review, Issue 4, 2015. (in Chinese) 